\title{
Eukaryal composition and diversity in anaerobic soils influenced by the novel chiral insecticide Paichongding
}

\author{
Xiaolin Zhu, Shaomin Zhou, Jing Guo, Xiyue Zhao, Guanghua Yang ${ }^{*}$ and Zhiqiang Cai ${ }^{*}$
}

\begin{abstract}
Paichongding (IPP) is a neonicotinoid chiral insecticide with independent intellectual property in China. IPP application can increase crop yield, and also lead to insecticide residue and pollution in soils, which will affect microbial population and community composition in soils. In this study, four different types of soils were employed to inquire into the impact of IPP on eukaryal community and species-group through pyrosequencing of $18 \mathrm{~S}$ rRNA gene amplicons. Fungal population differed in different soils at different days after IPP treatment (DAT). Eukaryal community species in CK (control check) groups were more rich than that with Paichongding sprayed at 5 DAT, while eukaryal species in CK soils at 60 DAT was relatively slight. Shannon's H'analysis indicated fungal species in CK soils were also higher at 5 DAT and relative lower at 60 DAT, except in soil C. There are also differences in the phyla and genus levels of the eukaryotic communities in the soil. After IPP application, the relative abundance of Nectriaceae increased 3-4 times in soil C. In soil F, Phaeosphaeriaceae increased to $57.3 \%$ at 5 DAT. The genus of Guehomyces, Aspergillus and Alternaria increased from 3.1 to $9.7,1.1$ to $4.6,1.5$ to $6.7 \%$ in soil $H$, respectively.
\end{abstract}

Keywords: Paichongding, Pyrosequencing, Eukaryal community, Soil eukaryal population, Anaerobic soils

\section{Introduction}

Soil microorganism play the most important roles on soil productivity and fertility, including organic matter decomposing, nutrient cycling, and soil aggregates forming (Six et al. 2004), they can change soil chemical and physical properties. Some bacteria and fungi are responsible for providing nutrients and essential materials, which can promote crop growth (Eo and Park 2016; Esitken et al. 2010). Pesticides are more and more popular in modern agriculture in order to control weeds, kill insects, improve the quality and yield of agricultural products. However, pesticides can enter soils via spraying draft during plant treatment, wash-off from treated foliage, release from seeds (Cycon et al. 2013). Pesticide residue in soil affect microbial community composition in soils by altering their population, enzyme activity and

\footnotetext{
*Correspondence: yguanghua@cczu.edu.cn; zhqcai@cczu.edu.cn Laboratory of Applied Microbiology and Biotechnology, School of Pharmaceutical Engineering \& Life Science, Changzhou University, Changzhou 213164, China
}

microbial diversity, which perhaps reduce soil fertility (Asad et al. 2017; Cai et al. 2016a, b; Zabaloy et al. 2012; Zhang et al. 2014).

Paichongding (IPP, 1-((6-chloropydidin-3-yl) methyl)7-methyl-8-nitro-5propoxy-1,2,3,5,6,7-hexahydroimidazo[1,2- $\alpha$-]-pyridine), is a novel neonicotinoid insecticide with independent intellectual property rights (Cai et al. 2016a, b, c; Fu et al. 2013). It has four stereoisomers (RR, SS, RS and $S R$-IPP) because of its two chiral carbon centers. IPP has higher insecticidal activity (4050 times) compared to imidacloprid-resistance pests, and also has low toxicity to human. In 2009, IPP production in China has reached 1000 tons and was sprayed for almost 3.3 million hectares (Fu et al. 2013).

Insecticides residue can disturb soil ecosystems, some bacteria and fungi are involved in insecticides and other organic pollutants degradation. Insecticides application and accumulation in environment can affect microbial communities diversity and composition (Asad et al. 2017; Cai et al. 2016a, b; Cycon et al. 2013). Accumulation of 
pesticide residues has been accelerated with the increase in crop growth. Many reports showed that insecticides have potential risk to the soil biochemical properties and it also changes ecosystems through concentrating along food chain (Zabaloy et al. 2012; Zhang et al. 2014). Hence, there is a need to investigate the effect of new insecticides on microbial population, composition and diversity in soils (Asad et al. 2017; Chen et al. 2017).

Previous studies have emphasized the biodegradation pathway and IPP behavior in soils (Cai et al. 2016c; Wang et al. 2016). The effects on bacterial community and soil enzyme activity of IPP were also studied, several studies have addressed the effect of IPP on bacterial community (Cai et al. 2015b, 2016a, b; Chen et al. 2017); however, little information is available on the impact of IPP on soil fungal population and community. In this study, we used four different soils to understand the impact of IPP on soil fungal population and community in soils.

\section{Materials and methods}

Chemicals and soil samples

Paichongding (IPP, 1-((6-chloropydidin-3-yl)methyl)7-methyl-8-nitro-5-propoxy-1,2,3,5,6,7-hexahydroimidazo $[1,2-\alpha-]$-pyridine, chemical purity $98.3 \%$, formula weight FW 366)was manufactured from Jiangsu Kesheng Company Ltd. Soil samples from different location were sampled and used in this study, which were Paddy field on desalting muddy polder (soil C, GB/T-H2121315), yellow paddy soil (soil H, GB/T-A2111511), yellow loam soil (soil F, GB/T-A2111411) and Huangshi soil (soil J, GB/T-G2511211), respectively. The soils were sampled in crop fields located in Cixi (Zhejiang Province), Jingzhou (Hubei Province), Longquan (Fujian Province) and
Changzhou (Jiangsu Province), China. The basic physicochemical characteristics of soils were showed in Table 1.

\section{Experiments procedure}

To study the effect of Paichongding on eukaryal community in anaerobic soils, soil sample was separated into two sets: one was pre-incubated for acclimatizing microorganism in soils without IPP inoculation (CK set), and the second was inoculated with $10 \mathrm{mg} \mathrm{kg}^{-1}$ of IPP in soil. All the experiments of each soil were carried out in triplicate. The soil moisture content was maintained at about $60 \%$. The incubation temperature was $25 \pm 1{ }^{\circ} \mathrm{C}$. Ten grams of soil were collected from the flask to counter fungal population and DNA extraction at 5, 20, 30, 45, 60, 75 and 100 days after treatment (DAT). Soil fungal population counting was assayed through most probable number method (MPN) according with previous reported methods (Cai et al. 2016a, b).

\section{Soil DNA extraction and pyrosequencing, bioinformatics analysis}

Soil DNA extraction was based on the manufacturer's protocol (FastDNA Spin kit, MP Biomedicals, USA). The total DNA was purified using agarose gel electrophoresis. Pure DNA was extracted using extraction kit (Roche). DNA quality was assessed with a ScanDrop 200 spectrophotometer.

The primers ITS1F (5'-CTTGGTCATTTAGAGGAAGTAA-3 ${ }^{\prime}$ ) and ITS2R (5'-GCTGCGTTCTTCATCGATGC-3') were used to amplify $18 \mathrm{~S}$ rRNA gene fragment. The PCR reaction program and PCR products purification was according with previous reported methods (Cai et al. 2015a, 2016a). Totally 590,023 18S rRNA

Table 1 Physico-chemical characteristics of the experimental soils

\begin{tabular}{|c|c|c|c|c|}
\hline Characteristics & Yellow loam soil (F) & Huangshi soil (J) & Paddy field on desalting muddy polder (C) & Yellow paddy soil (H) \\
\hline Location & Longquan, Fujian Province & Changzhou, Jiangsu Province & Cixi, Zhejiang Province & Jingzhou, Hubei Province \\
\hline $\mathrm{pH}\left(\mathrm{H}_{2} \mathrm{O}\right)$ & 6.63 & 5.95 & 8.25 & 6.70 \\
\hline $\mathrm{OM}, \%$ & 2.67 & 1.52 & 2.48 & 1.98 \\
\hline $\mathrm{CEC}, \mathrm{cmol} \mathrm{kg}^{-1}$ & 14.09 & 7.11 & 16.1 & 13.9 \\
\hline Clay, $\%$ & 38.7 & 33.5 & 24.3 & 33.0 \\
\hline Silt, \% & 50.4 & 49.8 & 71.1 & 51.2 \\
\hline Sand, $\%$ & 10.9 & 16.7 & 4.6 & 15.8 \\
\hline \multicolumn{5}{|l|}{ Texture, \% (mm) } \\
\hline$<0.01$ & 67.4 & 60.7 & 64.7 & 67.4 \\
\hline $0.01-0.09$ & 28.3 & 32.6 & 34.5 & 28.3 \\
\hline$>0.09$ & 4.3 & 6.7 & 0.8 & 4.3 \\
\hline Total N, \% & 0.24 & 0.08 & 1.03 & 0.12 \\
\hline $\mathrm{P}, \mathrm{mg} \mathrm{kg}^{-1}$ & 21.25 & 7.65 & 15.37 & 10.25 \\
\hline $\mathrm{K}, \mathrm{g} \mathrm{kg}^{-1}$ & 13.47 & 10.7 & 22.9 & 5.22 \\
\hline
\end{tabular}

OM organic matter, CEC cation exchange capacity 
sequence reads were filtered, Trimmomatic was applied to denoised and processed. The sequences were analyzed through QIIME. Operational taxonomic units (OTUs) was used at $97 \%$ sequence similarity. The methods used for Rarefaction curves, Shannon-Wiener curves, eukaryal communities composition, Venn and PcoA analysis, and eukaryal genus heatmap were in accordance with the previous reported methods (Cai et al. 2015a, 2016a). The metagenomic sequencing data were deposited in the BioProject database (BioProject ID: PRJNA425705).

\section{Results}

\section{Effect of IPP on soil eukaryal population}

The effect of IPP on fungal population in anaerobic soils was indicated in Fig. 1. The total number of fungi in soil C decreased significantly before 60 DAT compared with CK group, and then increased at 75 and 100 DAT. In soil $\mathrm{F}$, the total number of fungi increased at 30 and $45 \mathrm{DAT}$, then decreased significantly at 100 DAT. Fungal population was unchangeable compared with the CK group at 20 and $30 \mathrm{DAT}$, after $45 \mathrm{DAT}$ the fungal population decreased in soil $\mathrm{J}$. While in soil $\mathrm{H}$, fungal population increased significantly before 45 DAT, and then keep unchangeable compared with the CK group.

\section{Eukaryal community species diversity and structure}

Species diversity of microbial community was shown in Fig. 2a. The results showed that eukaryal community species in CK group have more diverse than that in samples with Paichongding application at 5 DAT, while eukaryal species in CK soils at 60 DAT was relatively lower. Shannon's H' analysis indicated fungal species in CK soils were also higher at 5 DAT and relative lower at $60 \mathrm{DAT}$, except in $\mathrm{C}$ soil. The results of rarefaction analysis (Fig. 2a) were also almost the same compared with Shannon's H' (Fig. 2b).

All the reads in Fig. 3 were belonged to the family of fungi. Ascomycota were the most abundant phylum in all samples (33.9-95.6\%, Fig. 5a), apart from soil F without Paichonging sprayed and soil J with IPP sprayed at 5 and 60 DAT. The relative abundance of Basidiomycota increased from 26.1 to $33.0 \%$ in soil $\mathrm{H}$, from 43.5 to $79.2 \%$ in soil J after IPP application. There were four phyla identified in this study, Ascomycota, Basidiomycota, Chytridiomycota and Zygomycota. Zygomycota was only found
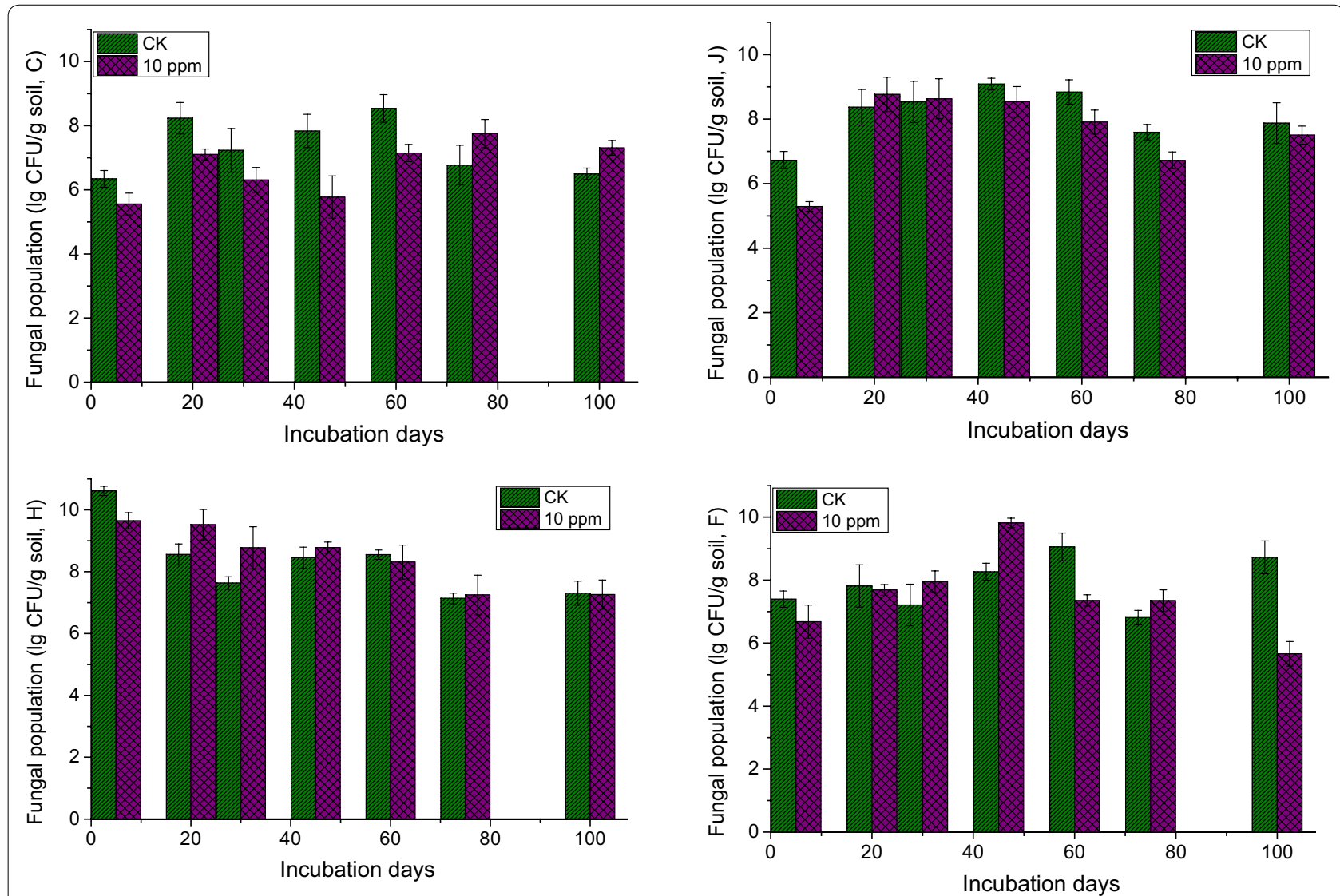

Fig. 1 Effect of IPP on soil fungal population for different incubation periods in soils 

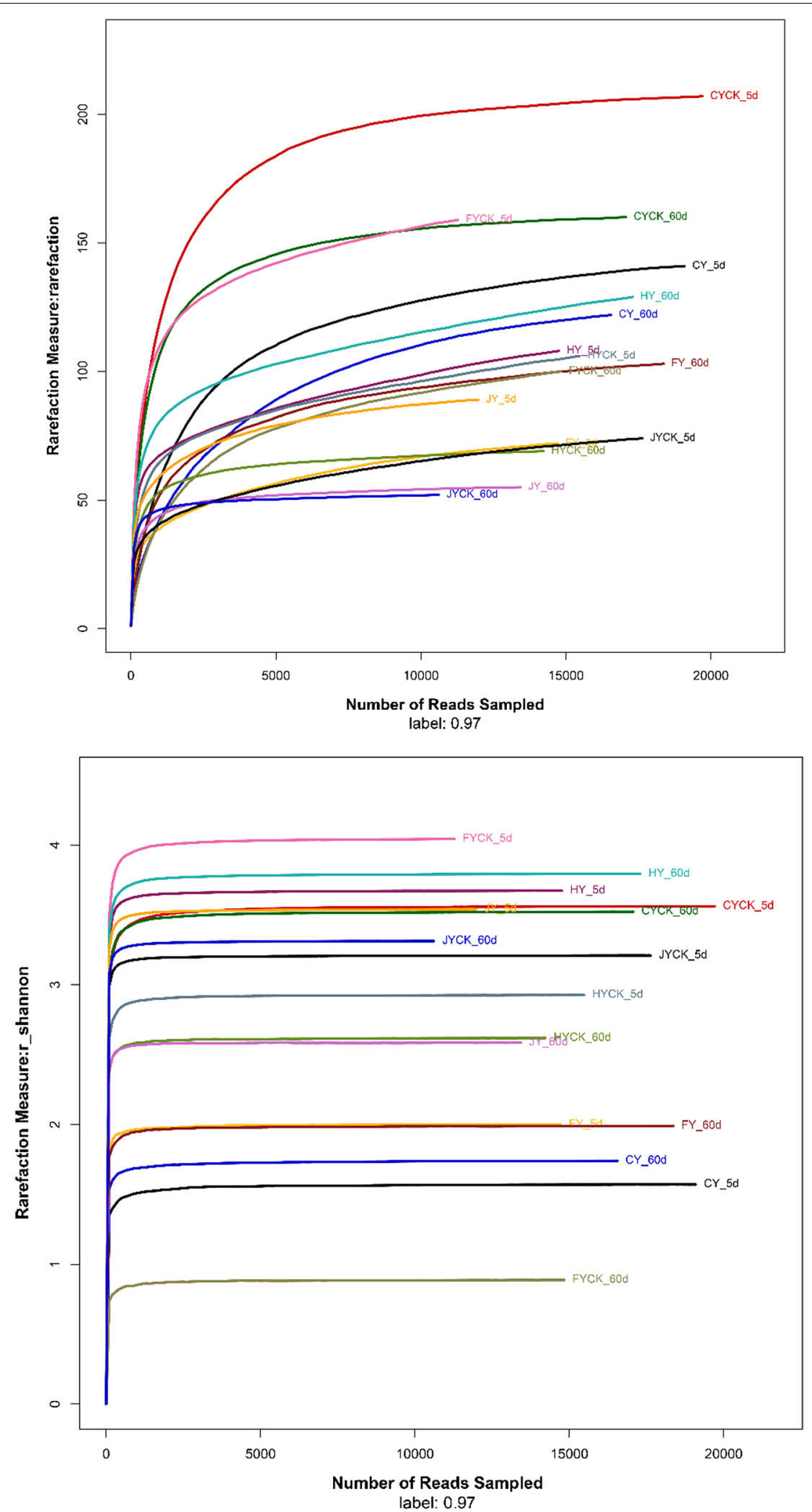

Fig. 2 Rarefaction curves (a) and Shannon-Wiener curves (b) (CYCK: CK of soil C; CY: soil C; FY: soil F; FYCK: CK of soil F; HY: soil H; HYCK: CK of soil H; JY: soil J; JYCK: (K of soil J) 

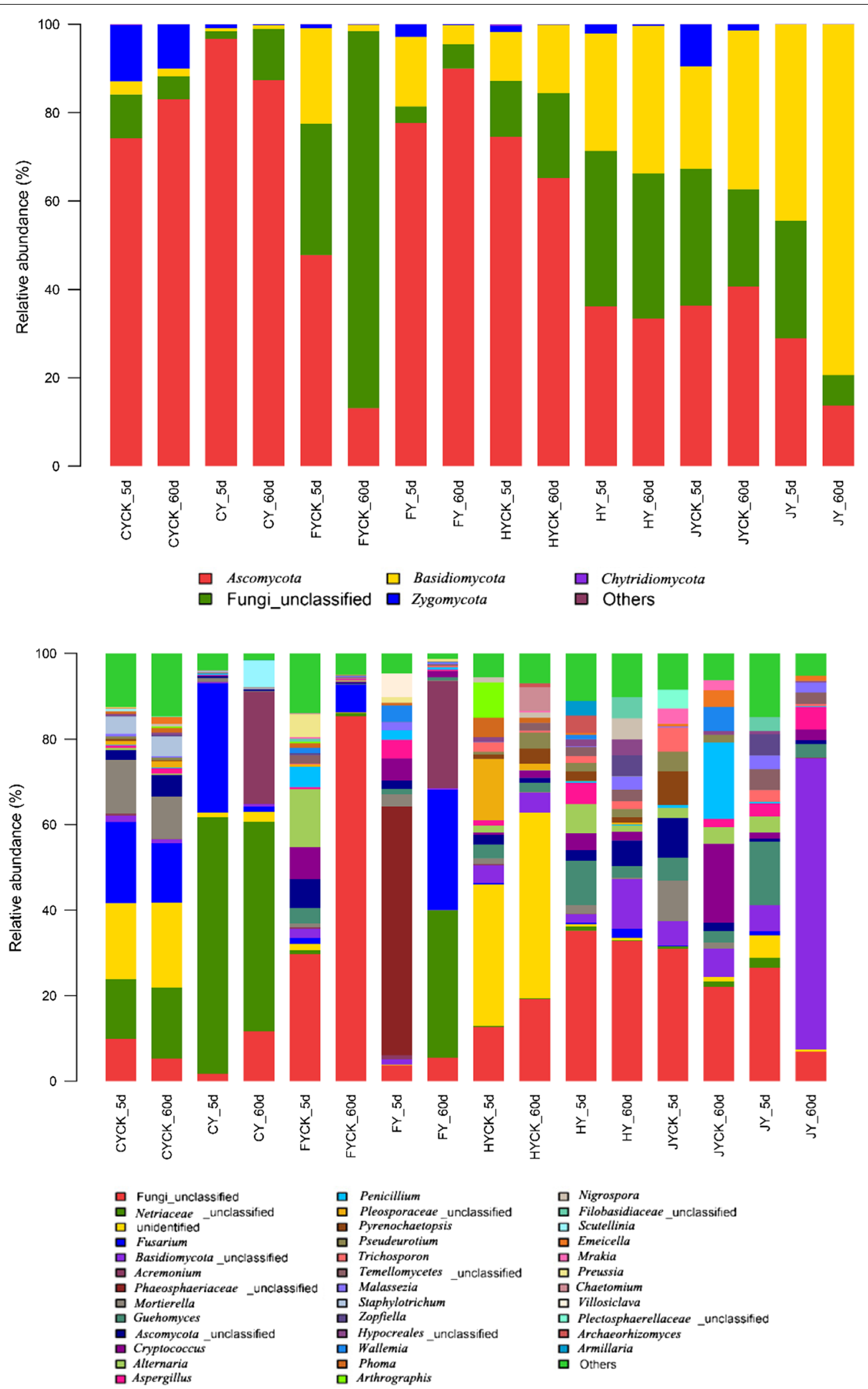

口 Nigrospora

ㅁ Filobasidiaceae unclassified

든linia

口 Emeicella

ㅁ Mrakia

ㅁ Preussia

Chaelomium

ㄴ.

Preciospharellaceae_unciassified

ㅁ Archaeorhizomyces

A Armillaria

Aspergillu.

ㅁ Phoma
$\square$ Arthrographis

Fig. 3 Eukaryal composition of the different communities (a Percentage of relative read abundance of eukaryal phyla within each community; $\mathbf{b}$ Percentage of relative read abundance of eukaryal genus within each community) 

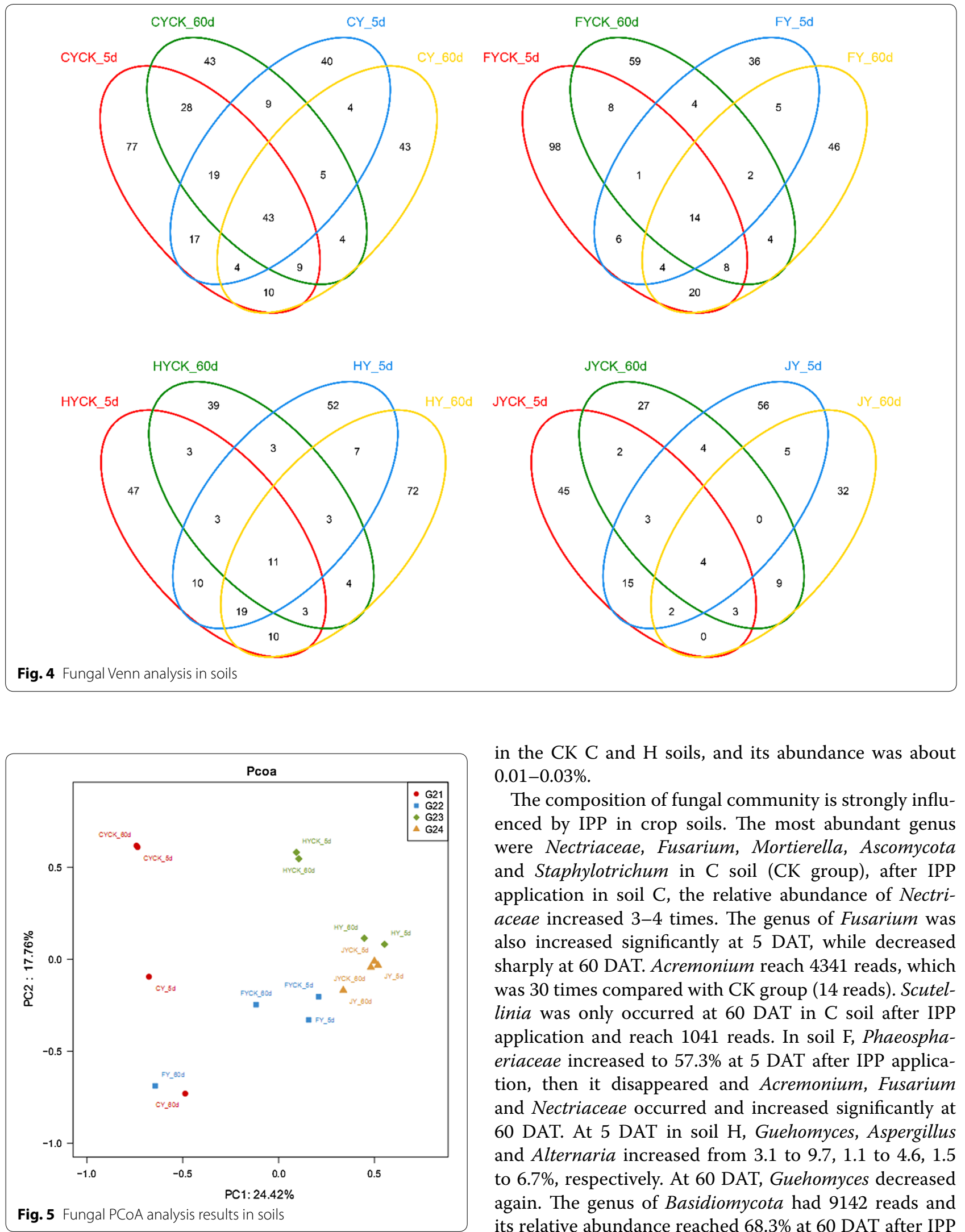

in the $\mathrm{CK} \mathrm{C}$ and $\mathrm{H}$ soils, and its abundance was about $0.01-0.03 \%$.

The composition of fungal community is strongly influenced by IPP in crop soils. The most abundant genus were Nectriaceae, Fusarium, Mortierella, Ascomycota and Staphylotrichum in C soil (CK group), after IPP application in soil C, the relative abundance of Nectriaceae increased 3-4 times. The genus of Fusarium was also increased significantly at 5 DAT, while decreased sharply at 60 DAT. Acremonium reach 4341 reads, which was 30 times compared with CK group (14 reads). Scutellinia was only occurred at 60 DAT in C soil after IPP application and reach 1041 reads. In soil F, Phaeosphaeriaceae increased to $57.3 \%$ at 5 DAT after IPP application, then it disappeared and Acremonium, Fusarium and Nectriaceae occurred and increased significantly at 60 DAT. At 5 DAT in soil H, Guehomyces, Aspergillus and Alternaria increased from 3.1 to 9.7, 1.1 to 4.6, 1.5 to $6.7 \%$, respectively. At 60 DAT, Guehomyces decreased again. The genus of Basidiomycota had 9142 reads and its relative abundance reached $68.3 \%$ at 60 DAT after IPP application. 

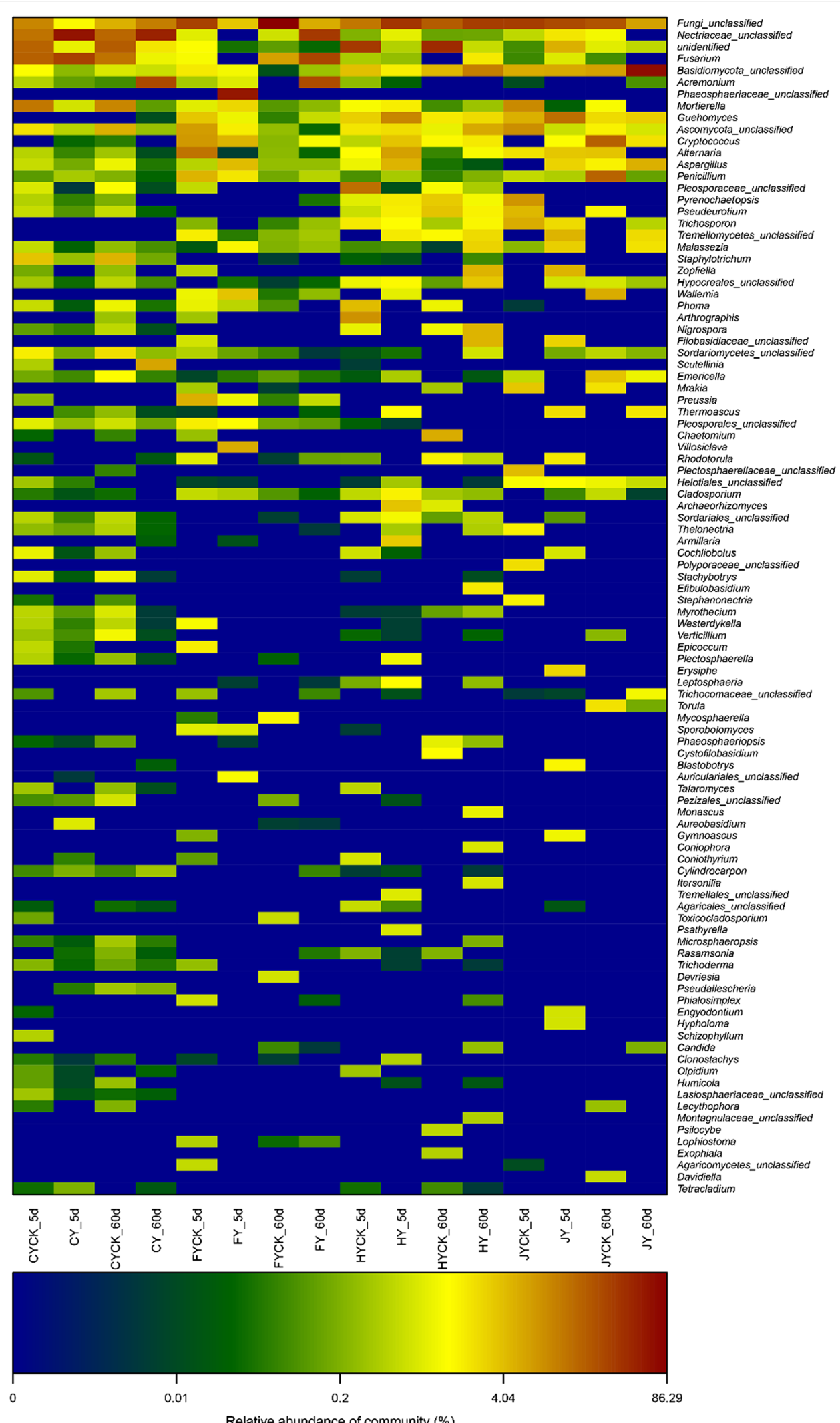

Relative abundance of community (\%)

Fig. 6 Distribution heatmap of eukaryal genus arranged by hierarchical clustering in soils with different treatment 
The overlaps of community were displayed as three-set Venn diagrams (Fig. 4). Soil C and $\mathrm{H}$ shared almost identical number of OTUs. The shared OTUs keep unchangeable after IPP application. The OTUs in soils with IPP sprayed was lower than that in CK soil. After application of IPP, OTUs increased in soil $\mathrm{F}$ and J. In soil $\mathrm{C}$, there were 141, 207, 122 and 141 OTUs in CY-5d, CYCK-5d, CY-60d and CYCK-60d soil samples, and they shared 43 same OTUs.

\section{Discussion}

The research results indicated that significant difference of fungal population existed before and after IPP spraying in anaerobic soils. The degradation efficiency and transformation rate of organic pollutants (such as pesticide, germicide and insecticide, etc.) in soils mainly depended on soil microbial population and its activity (Asad et al. 2017; Cycon et al. 2013; Eo and Park 2016; Kuppusamy et al. 2016). The chemical and biological processes in soils can lead to fungal population, including enzymatic reaction and organic pollutants biological behavior etc., response to an ecological disturbance, which depend on the presence of pesticide or insecticide (Asad et al. 2017; Cycon et al. 2013; Eo and Park 2016; Zabaloy et al. 2012). The change of microbial population and soil enzyme activity after insecticide application varied differently in different soils, which lead to hardly predict with certain model, because many inter reactions in soils existed in different conditions. The results indicated that the soil enzyme activity and fungal population were affected after IPP application, soil enzyme activity is one of key factors during nutrient cycling in soils (Asad et al. 2017; Cai et al. 2015a, 2016b). Neonicotinoid insecticides are high toxicity to vertebrates, and its use has been partly restricted for their effects on pollinators (Zeng et al. 2013). This study also suggested that IPP also can inhibit fungal population and has toxicity to fungi, which are in accord with published reports (Cai et al. 2016a, b).

In this study, we investigated the correlation of the eukaryal community patterns to with IPP sprayed and CK soil sample using the method of conducted the PCoA (Principal Coordinates Analysis), which based on sample similarity matrix from the same soil. It revealed the PCoA results (Fig. 5) that samples may be differentiated after IPP sprayed, whereas samples from same soils were nearly together because they shared similar community structure patterns. The soil fungal community after spraying IPP shared higher similarity according to the clustered heatmap analysis, which based on the eukaryal community at the genus level (Fig. 6). The eukaryal profile in CK soils was distant than that soils after Paichongding sprayed.
The organic matter $(\mathrm{OM})$ content is the key factor during IPP biodegradation in soils. Higher OM content brought about higher IPP degradation rate and higher microbial population (Cai et al. 2016a, b), previous studied also showed the higher TC content can enhance microorganism growth (Hirano et al. 2007; Eo and Park 2016; Chen et al. 2016). Eukaryal community diversity was less diverse after IPP sprayed in soils, Shannon's H and rarefaction were also relative low, which was with accordance with the results of IPP effect on bacterial community and species.

This study showed the IPP can affect microbial population and community species. IPP could make some of phyla and genus increase or decrease in soils. These variation was presumably due to IPP spraying and properly accumulation of IPP metabolites in soils (Cai et al. 2015a, b, 2016a, b; Fu et al. 2013; Li et al. 2013; Wang et al. 2013). The heatmap also revealed clearly that the eukaryal communities were different in same soil (Fig. 6). Specific eukaryal communities and populations occurred under specific stresses in environment, which indicated that the change of microbial communities composition was caused by specific environmental stresses, such as biodegradation intermediates accumulation, interaction with other organic pollutants in soils.

\section{Abbreviations}

IPP: Paichongding; DAT: days after IPP treatment; CK: control check; soil C: paddy field on desalting muddy polder; soil H: yellow paddy soil; soil F: yellow loam soil; soil J: Huangshi soil; MPN: probable number method; OTUs: operational taxonomic units; OM: organic matter.

\section{Authors' contributions}

$S Z, J G, X Z$ and GY carried out the experiments; SZ and JG wrote the paper; XZ, GY and ZC designed the research; ZC obtained the funding. All authors read and approved the final manuscript.

\section{Acknowledgements}

We thank the subjects for participating in the study. The authors gratefully acknowledge the generous support of the National Natural Science Foundation of China and Natural Science Foundation of Jiangsu Province, China.

\section{Competing interests}

The authors declare that they have no competing interests.

\section{Availability of data and materials}

The data on which the conclusions are made are all presented in this paper.

\section{Consent for publication}

Not applicable.

\section{Ethics approval and consent to participate}

Not applicable.

\section{Funding}

The research was financially supported by the Grants "National Natural Science Foundation of China" (Project No. 11275033) and "Natural Science Foundation of Jiangsu Province, China" (Project No. BK20151185). 


\section{Publisher's Note}

Springer Nature remains neutral with regard to jurisdictional claims in published maps and institutional affiliations.

Received: 13 December 2017 Accepted: 13 April 2018

Published online: 18 April 2018

\section{References}

Asad MA, Lavoie M, Song H, Jin Y, Fu Z, Qian H (2017) Interaction of chiral herbicides with soil microorganisms, algae and vascular plants. Sci Total Environ 15:1287-1299

Cai Z, Wang J, Ma J, Zhu X, Cai J, Yang G (2015a) Anaerobic degradation pathway of the novel chiral insecticide Paichongding and its impact on bacterial communities in soils. J Agric Food Chem 63:7151-7160

Cai Z, Zhang W, Li S, Ma J, Wang J, Zhao X (2015b) Microbial degradation mechanism and pathway of the novel insecticide Paichongding by a newly isolated Sphingobacterium sp. P1-3 from soil. J Agric Food Chem 63:3823-3829

Cai Z, Ma J, Wang J, Cai J, Yang G, Zhao X (2016a) Impact of the novel neonicotinoid insecticide Paichongding on bacterial communities in yellow loam and Huangshi soils. Environ Sci Pollut Res 23:5134-5142

Cai Z, Rong Y, Chen J, Wang J, Ma J, Zhang W, Zhao X (2016b) Effects of the novel cis-nitromethylene neonicotinoid insecticide Paichongding on enzyme activities and microorganisms in yellow loam and Huangshi soils. Environ Sci Pollut Res 23:7786-7793

Cai Z, Ma J, Wang J, Rong Y, Chen J, Li S, Zhang W, Zhao X (2016c) Aerobic biodegradation kinetics and pathway of the novel cis-nitromethylene neonicotinoid insecticide Paichongding in yellow loam and Huangshi soils. Appl Soil Ecol 98:150-158

Chen J, Sun X, Li L, Liu X, Zhang B, Zheng J, Pan G (2016) Change in active microbial community structure, abundance and carbon cycling in an acid rice paddy soil with the addition of biochar. Eur J Soil Sci 67:857-867

Chen J, Zhou S, Rong Y, Zhu X, Zhao X, Cai Z (2017) Pyrosequencing reveals bacterial communities and enzyme activities differences after application of novel chiral insecticide Paichongding in aerobic soils. Appl Soil Ecol 112:18-27

Cycon M, Markowicz A, Borymski S, Wojcik M, Piotrowska-Seget Z (2013) Imidacloprid induces changes in the structure, genetic diversity and catabolic activity of soil microbial communities. J Environ Manag 131:55-65
Eo J, Park KC (2016) Long-term effects of imbalanced fertilization on the composition and diversity of soil bacterial community. Agric Ecosyst Environ 231:176-182

Esitken A, Yildiz HE, Ercisli S, Donmez MF, Turan M, Gunes A (2010) Effects of plant growth promoting bacteria (PGPB) on yield, growth and nutrient contents of organically grown strawberry. Sci Hortic-Amsterdam 124:62-66

Fu Q, Wang Y, Zhang J, Zhang H, Bai C, Li J, Wang W, Wang H, Ye Q, Li Z (2013) Soil microbial effects on the stereoselective mineralization, extractable residue, bound residue and metabolism of a novel chiral cis neonicotinoid, Paichongding. J Environ Manag 61:7689-7695

Hirano T, Ishida T, Oh K, Sudo R (2007) Biodegradation of chlordane and hexachlorobenzenes in river sediment. Chemosphere 3:428-434

Kuppusamy S, Thavamani P, Megharaj M, Venkateswarlu K, Lee YB, Naidu R (2016) Pyrosequencing analysis of bacterial diversity in soils contaminated long-term with PAHs and heavy metals: implications to bioremediation. J Hazard Mater 317:169-179

Li J, Zhang J, Li C, Wang W, Yang Z, Wang H (2013) Stereoisomeric isolation and stereoselective fate of insecticide Paichongding in flooded paddy soils. Environ Sci Technol 47:12768-12774

Six J, Bossuyt H, Degryze S, Denef K (2004) A history of research on the link between (micro) aggregates, soil biota, and soil organic matter dynamics. Soil Till Res 79:7-31

Wang H, Yang Z, Liu R, Fu Q, Zhang S, Cai Z, Li J, Zhao X, Ye Q, Wang W, Li Z (2013) Stereoselective uptake and distribution of the chiral neonicotinoid insecticide, Paichongding, in Chinese pak choi (Brassica campestris ssp. chinenesis). J Hazard Mater 262:862-869

Wang J, Chen J, Zhu W, Ma J, Rong Y, Cai Z (2016) Isolation of the novel chiral insecticide Paichongding (IPP) degrading strains and biodegradation pathways of RR/SS-IPP and SR/RS-IPP in an aqueous system. J Agric Food Chem 64:7431-7437

Zabaloy MC, Gomez E, Garland JL, Gomez MA (2012) Assessment of microbial community function and structure in soil microcosms exposed to glyphosate. Appl Soil Ecol 61:333-339

Zeng GG, Chen M, Zeng ZT (2013) Risks of neonicotinoid pesticides. Science 340:1403

Zhang QM, Zhu LS, Wang J, Xie H, Wang JH, Wang FH, Sun FX (2014) Effects of fomesafen on soil enzyme activity, microbial population, and bacterial community composition. Environ Monit Assess 186:2801-2812

\section{Submit your manuscript to a SpringerOpen ${ }^{\circ}$ journal and benefit from:}

- Convenient online submission

- Rigorous peer review

- Open access: articles freely available online

- High visibility within the field

- Retaining the copyright to your article

Submit your next manuscript at $\boldsymbol{\nabla}$ springeropen.com 